\title{
VIVENCIANDO A GRAVIDEZ: PROCESSOS E SUB- PROCESSOS DE UMA TEORIA FUNDAMENTADA NOS DADOS
}

Sônia Silva Marcon *

Este artigo apresenta os resultados de um estudo qualitativo, que adotou como linha metodológica a "Grounded Theory", e como método de coleta de dados a observação participante. O objetivo foi explorar e compreender o período da gravidez, a partir da perspectiva de mulheres em estado de gravidez. Os dados foram coletados junto a quatro grupos amostrais, totalizando 96 mulheres, no período de janeiro a dezembro de 1987. Os resultados do estudo deram origem a uma teoria "substantive" (GLASER \& STRAUSS, 1967) em desenvolvimento, "Vivenciando a Gravidez": processo dinâmico que ocorre na vida da mulher dentro de um contexto espaçotemporal. A vivência deste processo pode ou não ser planejada e se dá em quatro etapas seqüenciais e inter-relacionadas: Precedendo o Início da Gravidez, o Início, o Meio e o Fim da Gravidez.

UNITERMOS: mulher, gravidez, vivenciando a gravidez, experiência vivida

\section{INTRODUÇÃO}

O período de gravidez (e a gestação em si) já foi e continua sendo muito estudado do ponto de vista de suas alterações morfológicas, funcionais e psicológicas. No entanto, a maioria dos estudos tem abordado os problemas das gestantes a partir da ótica de profissionais, ou então os dados são colhidos num determinado corte do espaço temporal, o que os tornam restritos a um determinado ponto do processo gestacional. Por isto, considerei que o que faltava para uma assistência mais adequada à mulher em estado de gravidez era o aprofundamento e a compreensão do período de gestação enquanto fenômeno experienciado pelo ser humano. Neste sentido, o objetivo deste estudo foi explorar, para compreender, o período de gestação a partir da percepção de mulheres em estado de gravidez, o que deu origem a uma teoria substantiva denominada "Vivenciando a Gravidez".

\footnotetext{
* Professor Adjunto da Universidade Estadual de Maringá-PR. Doutoranda em Filosofia da Enfermagem na UFSC
} 


\section{FUNDAMENTAÇÃO TEÓRICA}

"Vivenciando a gravidez", portanto, é uma teoria "substantive" (GLASER \& STRAUSS, 1967) em desenvolvimento, que foi gerada a partir de um estudo que adotou como linha metodológica básica a "Grounded Theory", ou Teoria Fundamentada nos Dados (GLASER \& STRAUSS, 1967), com o intuito de explorar e compreender a experiência vivida pelas mulheres em estado de gravidez, a partir de suas próprias perspectivas.

Esta metodologia tem suas raízes no Interacionismo Simbólico, e seu propósito é gerar teoria substantiva que favoreça a compreensão de fenômenos sociais e psicológicos (CHENITZ \& SWANSON, 1986:2). Teoria substantiva, segundo GLASER \& STRAUSS, (1967:32-43), é aquela desenvolvida dentro de uma área de investigação sociológica substantiva ou empírica e, durante o seu desenvolvimento, os constructos e conceitos são originados dos dados e as hipóteses são testadas tal como elas emergem da pesquisa (FIELD \& MORSE, 1985:23).

A sua construção segue pelo menos três pressupostos: o de que toda experiência humana é um processo que se encontra em constante evolução; o de que a construção da teoria envolve ambas, a abordagem dedutiva e a indutiva; e a de que devem existir vários grupos amostrais, os quais são comparados entre si ao longo do estudo, o que dá origem aos conceitos de amostragem teórica e saturação de categorias (GLASER \& STRAUSS, 1967:52).

\section{METODOLOGIA}

O estudo, do tipo qualitativo, foi desenvolvido junto a mulheres grávidas, na cidade de Florianópolis, no período de janeiro a dezembro de 1987. O método de coleta de dados utilizado foi a Observação-Participante (LEININGER, 1985:523 ), sendo que o papel adotado por mim durante toda a coleta de dados foi o de observadora e participante (PEARSALL, 1965:37-8). Além disso, a minha participação foi do tipo "conhecida" (LOFLAND, 1971:93-5), ou seja, as gestantes que compuseram os grupos amostrais foram informadas sobre o estudo e concordaram em participar do mesmo.

Foram entrevistadas e observadas noventa e seis gestantes em diferentes etapas de gravidez, as quais constituíram os seis grupos amostrais utilizados na análise comparativa dos dados. Algumas gestantes foram entrevistadas uma única vez; outras, mais de dez vezes; enquanto a grande maioria foi entrevistada entre três 
e cinco vezes.

Obedecendo a um dos propósitos da metodologia utilizada, defini de forma pré-determinada a composição apenas do primeiro grupo amostral. A saturação teórica ou de categorias, "momento no qual não são mais encontrados dados novos ou adicionais em determinado grupo" (WILSON, 1977), constituiu um dos principais critérios adotados para a definição do momento em que novos grupos deveriam ser buscados. E a amostragem teórica, processo no qual o pesquisador, após coletar, codificar e analisar os dados de cada grupo amostral toma algumas decisões em relação as quais os tipos de dados ainda devem e/ou precisam ser coletados e onde os mesmos podem ser encontrados (WILSON, 1977) foi o critério adotado na definição dos outros cinco grupos amostrais. A análise dos dados, através do emprego do método comparativo constante, resultou na teoria substantiva em desenvolvimento denominada "Vivenciando a gravidez".

\section{ESTRUTURA DO ESTUDO E APRESENTAÇÃO DOS RESULTADOS}

Os dados do estudo são apresentados já imbuídos de minhas análises e reflexões pessoais sobre suas possíveis relações e, portanto, sob a forma de resultados. Neste tópico, num primeiro momento, relato como ocorreram a evolução do estudo e a identificação das etapas que o compõem; num segundo momento, apresento a estrutura e organização que dei aos dados a partir do que consegui captar sobre a forma como as mulheres vivenciavam esta experiência. E, ao final, faço referência aos processos longitudinais que foram identificados permeando toda a evolução da experiência de vivenciar uma gravidez.

Além disso, esta apresentação é intercalada com algumas falas, com o intuito de fornecer ao leitor uma idéia dos dados que me ajudaram a identificar os aspectos relevantes desta experiência. Para facilitar a visualização do conjunto, no Quadro I apresento esquematicamente as etapas, processos e subprocessos que compõem o "Vivenciando a Gravidez", e no texto, para facilitar o acompanhamento das estruturas identificadas, cada etapa é colocada em caixa alta e negrito e acompanhada de um número simples; os processos e subprocessos correspondentes, também em negrito, são acompanhados de números com dois e três dígitos respectivamente, o que deu ao artigo uma estrutura própria, como pode ser observado no exemplo a seguir:

1 - PRECEDENDO O INÍCIO - $1^{\text {a }}$ etapa da experiência

1.1 - Vivenciando um relacionamento sexual - $1^{\circ}$ processo desta etapa

1.1.1 - Tendo vida sexual - $1^{\circ}$ sub-processo deste processo 
QUADRO 1 - VIVENCIANDO A GRAVIDEZ: ETAPAS, PROCESSOS E SUBPROCESSOS

\begin{tabular}{|l|l|l|}
\hline \multicolumn{1}{|c|}{ ETAPAS } & \multicolumn{1}{|c|}{ PROCESSOS } & \multicolumn{1}{c|}{ SUB-PROCESSOS } \\
\hline Precedendo o Início & $\begin{array}{l}\text { - Vivenciando um relacio- } \\
\text { namento sexual }\end{array}$ & $\begin{array}{l}\text { - Tendo vida sexual } \\
\text { - Elaborando um projeto } \\
\text { de vida sexual }\end{array}$ \\
\hline Início da gravidez & - Descobrindo-se grávida & $\begin{array}{l}\text { - Suspeitando-se grávida } \\
\text { - Procurando uma certeza } \\
\text { - Confirmando a gravidez } \\
\text { - Vivendo o processo de } \\
\text { aceitação do resultado } \\
\text { - Começando a perceber a } \\
\text { presença da gravidez }\end{array}$ \\
\hline Meio da gravidez & - Estando grávida & $\begin{array}{l}\text { - Percebendo a presença } \\
\text { da gravidez } \\
\text { - Percebendo a criança }\end{array}$ \\
\hline Fim da gravidez & - Esperando nascer & $\begin{array}{l}\text { - Vivendo com ansiedade } \\
- \text { Percebendo alterações } \\
\text { do final da gravidez } \\
\text { - Percebendo a criança }\end{array}$ \\
\hline
\end{tabular}

\section{- A evolução do estudo}

No início do estudo procurei identificar e entender como as mulheres percebiam a si e a seu estado durante o período de uma gravidez. Porém, as análises premiliares dos dados obtidos demonstravam que para elas este período era percebido como um processo, uma vez que suas percepções se alteravam com o avanço da gestação, demonstrando tratar-se de um processo dinâmico, vinculado ao tempo e ao espaço:

"O maior problema foi no começo... depois não, estou bem que às vezes até esqueço que estou grávida". de inchar".

"Foi uma gravidez muito boa, só agora no fim que comecei a ter problema

A este processo denominei "Vivenciando a Gravidez". Ele inclui as percepções do "eu" fisico-anátomo-psicológico das gestantes e suas alterações ao longo do tempo, como em: 
"Os seios cresceram, ficaram enormes, sumiu a cintura, a barriga começou a ficar redonda, é tudo muito rápido...".

"Acho que fiquei totalmente diferente, no começo fiquei mais nervosa, mais irritada, agora me acho calma até demais e também acho que fiquei mais madura".

Inclui também as percepções do contexto, formado pelo ambiente familiar e físico de onde provinha cada uma das gestantes em estudo, como pode ser observado nas falas a seguir:

"Ele ficou mais carinhoso e fala mais coisas boas do que antes".

"O mais novo eu acho que está com ciúmes... medo de perder as regalias, mas ele está mais carinhoso, agora eu peço um beijo e ele dá... antes ele não fazia estas coisas, agora fica mais tempo junto, puxa mais conversa, só que nunca fala do nenê".

"Eu sinto que as pessoas estão me poupando, ficam tirando tarefas que eram minhas. Até no serviço, agora meu patrão não fica mais me mandando pra cima e pra baixo".

"Eu estou achando legal o relacionamento com as outras pessoas, parece haver mais ternura por parte de todos".

"Nos dias quentes as varizes ficam saltadas e os pés incham muito".

"Na primeira eu passei melhor, não inchava como agora, acho que é porque eu morava numa região mais alta e mais fria".

Durante algum tempo pensei que este processo se referia à experiência vivida pelas mulheres durante, exclusivamente, o período de uma gravidez. Isto porque era marcante o fato de a experiência de uma gravidez ser percebida e referida pelas gestantes como um processo dinâmico, já que envolvia e era influenciado pelas suas percepções na presença de diferentes, sucessivas e significativas mudanças e alterações nas mais variadas áreas de sua vida durante toda a gravidez/gestação.

Assim, a percepção das mulheres sobre a evolução em relação ao tempo na experiência de estar grávida, ditada apenas pela percepção de alterações, representou, durante algum tempo, o elemento central e norteador do estudo, até que a relação desta evolução com a experiência de um processo já vivido anteriormente pelas mulheres foi identificado. Descobri, então, que tudo começava antes mesmo da concepção e a partir da vivência de um processo maior, qual seja, o processo de vida, 
pois constatei que a percepção da evolução desta experiência se encontrava, de alguma forma, vinculada aos planos e projetos de pelo menos uma das áreas deste processo, que era a área sexual.

Assim sendo, a percepção da evolução da gravidez, ao invés de restringirse apenas à duração desse período, necessariamente também engloba um momento anterior à própria concepção, e que foi denominado "Precedendo o início da gravidez".

A percepção da evolução das alterações durante a gravidez, por sua vez, foi caracterizada não só pelo surgimento de mudanças ou alterações ao longo dos nove meses de gestação, mas também porque algumas destas alterações, de forma isolada ou em conjunto, foram percebidas pelas mulheres de forma diferente em relação a outras. Ou seja, identifiquei que as mulheres davam mais "valor" ou mais "peso" a algumas alterações do que a outras, pois elas interpretavam o seu surgimento como sendo um ponto de referência ao longo do período da gravidez.

Estes pontos de referência eram interpretados por elas como verdadeiros "marcos", e isto me permitia perceber que vivenciar o período de uma gravidez é uma experiência constituída de diferentes momentos ou etapas. Ou seja, eles eram delimitadores do início ou término de diferentes etapas processuais.

Com relação a esta questão, constatei que um mesmo acontecimento, para algumas mulheres, delimitava o início de um novo momento, para outras, o término de um outro já existente. Por exemplo, o fato de a criança começar a se mexer tanto foi referido pelas mulheres delimitando o fim do "início da gravidez", como o começo do "meio da gravidez". Além disso, ao mesmo tempo em que o surgimento de determinadas alterações era interpretado como um "marco" delimitador do início ou do término de um momento, conforme:

"Eu ainda estou no começo... a barriga nem aparece direito".

"Eu tenho muitos enjôos, não posso comer nada, não vejo a hora de passar este comecinho".

Em outras ocorre o desaparecimento das mesmas, como por exemplo em:

“Agora está tudo bem, sumiu toda aquela ruindade, o começo é sempre ruim".

E ainda pode acontecer alguma mudança na sua forma de apresentação:

"De vez em quando ainda tenho enjôo, mas não é mais como no começo... ih! credo, não gosto nem de lembrar!...".

Assim, um acontecimento podia marcar os limites destes momentos ou então 
ajudar em sua caracterização.

Logo, foi o modo como as mulheres percebiam e interpretavam as mudanças ocorridas no seu "eu" ao longo da gestação, tanto em relação ao estado físico, fisiológico e emocional que, aos poucos, levaram-me a constatar que, para elas, existem alguns acontecimentos durante o período de uma gravidez que lhes permitem identificar não só a existência, mas também os limites e as características de diferentes momentos da experiência de estar grávida. Estes diferentes momentos são rotulados pelas mulheres do Início, Meio e Fim da gravidez e eles constituem as diferentes etapas ou períodos da experiência de estar grávida.

As mulheres do estudo permitiram-me, desta maneira, identificar a existência de quatro etapas ou períodos que compõem a evolução do "Vivenciando a gravidez", quais sejam: 1) Precedendo o início da gravidez; 2) O Início; 3) O Meio e 4) o Fim da gravidez.

\section{- A organização dos dados}

A primeira etapa, (1) PRECEDENDO O INÍCIO DA GRAVIDEZ, basicamente começa a partir do momento em que a mulher passa a ter relação sexual com um parceiro do sexo oposto ou a planejar uma vida sexual e, teoricamente, termina com a concepção. Ela é caracterizada pela vivência de um processo que foi denominado de (1.1) "Vivenciando um Relacionamento Sexual", formado por dois sub-processos: "Tendo vida sexual" e "Elaborando um projeto de vida sexual".

A vivência do (1.1.1) "Tendo vida sexual" se dá em duas dimensões: uma prática, representada pela presença da atividade sexual na vida da mulher, e uma mental, representada pelos conhecimentos (sobre fisiologia da reprodução e métodos de anticoncepção) e atitudes da mulher relacionadas a esta prática, bem como pelo nível de consciência em relação ao próprio risco de engravidar.

"Eu não achava certo, antes eu até falava mal de quem tinha relação antes do casamento... mas quando vi, eu também esta tendo e, como não me cuidei, acabei assim".

A inter-relação existente entre estas duas dimensões determina, nas mulheres, um constante repensar sobre sua prática sexual, e isto, por sua vez, traz mudanças em seus conhecimentos e atitudes, que podem ou não interferir na consciência da mulher sobre seu risco de engravidar, e isto pode influenciar o tempo gasto e a forma de elaboração de um projeto em relação à vida sexual.

A vivência do (1.1.2) Elaborando um projeto de vida sexual ocorre a partir do momento em que a mulher possui atividade sexual, independente do fato de ela, conscientemente, elaborar ou não um projeto específico a esta área, ou seja, ela sempre vai ter um projeto de vida sexual, mesmo que elaborado de uma fôrma pouco estruturada. Este projeto consiste de um processo mental, consciente e/ou 
inconsciente, no qual a mulher, de tempos em tempos, reelabora, em nível teórico, um projeto de vida sexual, utilizando como suporte as três categorias (conhecimentos, atitudes e consciência) identificadas na dimensão mental do "Tendo vida sexual".

Quando os objetivos que a mulher tem em relação à sua prática sexual, e as prioridades que estabelece para a sua vida como um todo são elaborados conscientemente, estes determinam as decisões e as estratégias a serem tomadas em relação a ter ou não filho. Este sub-processo é constituído por cinco categorias (definindo objetivos da prática sexual, definindo prioridades em relação a ter ou não filhos, tomando uma decisão em relação a filhos, estabelecendo estratégias e colocando em prática) e durante a sua vivência é possível identificar a existência de um processo de decisão permeando toda a sua extensão.

A segunda etapa foi denominada (2) INÍ́cIO OU COMEÇO DA GRAVIDEZ, e corresponde, teoricamente, ao período existente desde a concepção ou o início das suspeitas de uma gravidez e vai até a época em que as mulheres começam a perceber os movimentos da criança ou o aumento mais acentuado.da barriga, o que geralmente ocorre por volta dos quatro/quatro meses e meio de gestação. Ele é formado por dois processos: Descobrindo-se grávida e Estando grávida.

O (2.1) Descobrindo-se grávida refere-se às experiências vivenciadas pelas mulheres para descobrirem sua gravidez. Inicia-se com as primeiras suspeitas de uma gravidez e só termina com a confirmação das mesmas. Sua característica principal reside no fato de toda a sua extensão ser marcada pela presença de incerteza quanto à existência ou não da gravidez. Isto, por sua vez, desencadeia uma série de sentimentos e situações nas quais a mulher, mentalmente, tanto pode começar a preparar-se para uma confirmação de suas suspeitas, quanto começar a utilizar mecanismos em que estas são negadas. Este processo é formado por três sub-processos, "Suspeitando-se grávida", "Procurando uma certeza" e "Confirmando a gravidez".

O (2.1.1) Suspeitando-se grávida surge quando a mulher verdadeiramente toma consciência da suspeita da gravidez, o que desencadeia na mesma a instalação de um "estado de alerta". Este, por sua vez, envolve sentimentos, pensamentos, ações e reações as mais variadas possíveis, de tal modo que todas as alterações percebidas são interpretadas de forma a aumentar ou afastar as suspeitas de gravidez.

"Apesar da gente não estar querendo pra agora, quando atrasou uns dias eu já fiquei achando que era gravidez".

O (2.1.2) Procurando uma certeza refere-se ao processo mental que se instala na mulher tão logo surge a suspeita da gravidez, com o intuito de saber se o que ela está pensando em relação à existência da mesma é real ou não. A sua vivência engloba processos mentais como associações, comparações, busca de informações, etc. 
“Já sou mãe de cinco, então quando começou a ruindade no corpo, eu logo vi que era gravidez".

Enquanto este sub-processo se caracteriza pela vivência de processos mentais, o (2.1.3) Confirmando a gravidez se caracteriza pela busca ativa de uma confirmação a suspeita, através da utilização de alguns recursos, tais como o uso de medicamento e chás, a ida ao médico e a realização do teste de gravidez.

Já o (2.2) Estando grávida caracteriza-se pelo fato de as mulheres se saberem grávidas, porém não se sentirem assim. Os eventos que delimitam esta fase são, de um lado, a confirmação da gravidez e, de outro, a percepção do início dos movimentos fetais ou o aumento acentuado da barriga. Surge diante da conscientização da mulher sobre a necessidade de assumir a gravidez como parte de sua vida e está relacionado ao processo mental desencadeado com vistas a trabalhar a aceitação da confirmação da gravidez e a adaptação a ser feita em vários aspectos da sua vida. Os dois sub-processos daí oriundos foram denominados de "Vivendo o processo de aceitação do resultado" e "Começando a perceber a presença da gravidez".

“...é uma coisa engraçada, eu sei que estou grávida, o exame deu positivo... mas não me sinto grávida. Pra você ter uma idéia,já estou de três meses e até hoje ando com modess na bolsa. Se precisar... (riso)".

(2.2.1) Vivendo o processo de aceitação do resultado corresponde aos primeiros tempos após a confirmação da gravidez. Refere-se ao conjunto de experiências e sentimentos vivenciados em relação à confirmação da gravidez e ao trabalho mental realizado com o objetivo, inicialmente, de subsidiar a decisão a ser tomada em relação a continuar ou não grávida e, mais tarde, de apoiar a decisão tomada, de forma consciente ou não, de continuar grávida. Ele se processa através de ponderações, sentimentos, reações, ações, mudanças, tentativas, etc.

Destaca-se na vivência deste processo o fato de ser praticamente aí que a mulher toma a decisão de continuar ou não grávida. Embora o estudo tenha sido realizado apenas com as mulheres que se "decidiram" a continuarem grávidas, foi possível identificar que para muitas delas esta decisão não existiu de forma concreta, ou seja, para muitas mulheres o continuar grávida foi uma decisão inerente à própria condição de estar grávida.

“Eu não queria engravidar, eu não podia... mas agora... bom, eu não tenho coragem de fazer nada...".

2.2.2 - Começando a perceber a presença da gravidez refere-se à vivência do processo que surge a partir da percepção de algumas mudanças, independente de as mulheres estarem aceitando ou não sua nova condição. este sub-processo caracteriza-se especialmente pela percepção de alguns incômodos causados pelas 
primeiras alterações, envolvendo a percepção de mudanças em si e nas pessoas e, ainda, nas experiências de novos sentimentos. Mudanças na fisiologia e no corpo são percebidas claramente como relacionadas à gravidez, mas mudanças no seu jeito de ser e no jeito de ser de outras pessoas em relação a ela, nesta fase, geralmente são percebidas apenas como possíveis de estarem relacionadas à gravidez.

Com relação às vivências experiênciadas durante o "Descobrindo-se grávida", é importante observar que, apesar do resultado positivo do teste de gravidez, as mulheres levam algum tempo sem se sentirem grávidas, e mais, que é durante este tempo que realmente tomam decisões em relação a continuar ou não grávidas.

A etapa seguinte, denominada (3) MEIO DA GRAVIDEZ, corresponde ao período vivido pelas mulheres dos quatro/quatro meses e meio até os oito/oito meses e meio de gestação. Tem início com a percepção do surgimento dos movimentos fetais e/ou do aumento acentuado da barriga, e se caracteriza pela vivência de um único processo, aqui denominado (3.1) Sentindo-se grávida.

Nele, a mulher deixa de apenas saber-se grávida para começar a sentir-se grávida. Uma de suas principais particularidades é o fato de as mulheres relatarem que diminuiu, desapareceu ou pelo menos atenuou-se a maioria da alterações percebidas como desagradáveis, passando a predominar as sensações, os sentimentos e os comportamentos desencadeados pela percepção da presença da criança.

Dois sub-processos são aqui identificados: "Percebendo a presença da gravidez" e "Percebendo a criança".

3.1.1. Percebendo a presença da gravidez refere-se ao conjunto dos sentimentos, atitudes, pensamentos e percepções das mulheres que já se conscientizam da gravidez. Isto é determinado particularmente pela percepção da relação existente entre as mudanças na fisiologia e no corpo, no seu jeito de ser e no das pessoas, como conseqüência da gravidez. Por outro lado essa consciência faz com que as mulheres iniciem um processo mental de pensar sobre a gravidez como um tempo de sua vida, o que provoca uma avaliação e/ou comparação em relação a uma outra gravidez, exprienciada por si mesma ou por outras pessoas.

“Logo no começo já fiquei quadrada, sem cintura, igual minha irmã”.

3.1.2 Percebendo a criança envolve a vivência de um processo mental no qual se incluem todos os tipos de sentimentos, pensamentos, medos, crenças, etc, relacionadas à percepção da presença da criança. É essencialmente a vivência deste sub-processo que caracteriza o sentir-se grávida. E mais, com os movimentos fetais praticamente se dissipam todas as dúvidas das mulheres quanto a "continuar" ou não grávida.

"Sinto uma alegria quando a criança mexe, é uma emoção... Nessa hora esqueço tudo: o quanto fiquei chateada com a gravidez, os problemas que ainda vou enfrentar...". 
A última etapa, (4) "O FIM DA GRAVIDEZ", tem início por volta das oito/oito meses e meio de gestação e termina com o parto. O início desta é marcado pelo retorno de algumas alterações percebidas pelas mulheres como desagradáveis.

Nela se insere o sub-processo (4.1) Esperando nascer já que nesta fase, tudo o que as mulheres fazem, pensam, sentem, etc., tem a ver com o compasso de espera do nascimento da criança.

“Eu não agüento mais, não vejo a hora de ganhar".

"Às vezes me dá vontade que nasça antes do tempo mesmo, mas aí eu fico com medo de acontecer alguma coisa de ruim...".

Em vista de uma série de preocupações e medos experienciados nesta fase, o "Vivendo com ansiedade" constitui um dos sub-processos do Esperando nascer, ao lado de "Percebendo alterações do final da gravidez" e "Percebendo a criança".

4.1.1 - Vivendo com ansiedade refere-se ao conjunto das vivências, que dão origem às três categorias identificadas: tendo ansiedade, tendo preocupações e tendo medos. O surgimento de qualquer problema, como um novo desconforto, ou alteração física desconhecida ou não esperada, normalmente vai conduzir as gestantes a uma potencialização da ansiedade, a ponto de determinar o surgimento de preocupações, especialmente em relação ao parto e à criança, e dos medos existentes neste período.

4.1.2 - Percebendo alterações do final da gravidez representa o conjunto dos sentimentos, atitudes, pensamentos e percepções que permeiam a consciência enquanto se aproxima o término da gravidez. Identifiquei aí quatro categorias: "Percebendo as alterações do final da gravidez", "Percebendo a si mesma", "Percebendo o período gestacional" e "Percebendo as pessoas".

Finalmente, o (4.1.3) Percebendo a criança, refere-se à continuidade dos processos nos quais as mulheres percebem toda espécie de sentimentos, medos, crenças, etc, relacionados à criança. É formado por duas categorias: "Percebendo a presença da criança" e "Imaginando a criança".

"Penso que ele não está bem desde o dia que venceu o prazo e ele não nasceu, fico achando que ele não está certo para nascer...".

Com relação à vivência desta última etapa, verifica-se que as mulheres sofrem demasiadamente do mal da ansiedade, causada principalmente por uma espera caracterizada pela insolvência, o que gera uma impaciência física e emocional e traz como conseqüência, em geral, a exacerbação da percepção de alterações vistas como desagradáveis.

“... não tenho mais posição boa para dormir, não consigo ficar sentada por muito tempo, já não consigo nem me limpar direito quando vou ao banheiro". 


\section{- A existência de processos longitudinais}

Do ponto de vista mais global, a experiência de "Vivenciar uma gravidez", além de englobar a vivência de processos e sub-processos tidos como específicos a cada uma das diferentes etapas, envolve também a vivência de outros processos, que, inseridos longitudinalmente na experiência de vivenciar a gravidez, nem sempre aparecem de forma explícita, mas apenas nas entrelinhas. Dentre estes processos destaca-se o "Buscando/Recebendo informações", o "Tomando decisões", o "Percebendo sentimentos", o "Percebendo alterações", etc.

Por exemplo, com relação ao Tomando decisões, durante a etapa do Precedendo o início, percebeu-se que as mulheres precisam tomar uma série de decisões, entre as quais a de ter ou não um relacionamento sexual; a de utilizar ou não um método de anticoncepção; a de como saber sobre os métodos de anticoncepção e a de escolher o tipo e a forma de utilização dos mesmos. Durante o Início da gravidez, mais precisamente durante a vivência do Descobrindo-se grávida, as decisões tomadas estão relacionadas a quem ela pode ou não manifestar suas suspeitas de uma gravidez, a como acabar com a suspeita, etc. No Estando grávida, a decisão mais importante é se continua ou não grávida, o que envolve decisões menores, tais como a de iniciar ou não, e freqüentar ou não um serviço de pré-natal, e, se vai freqüentar, qual será o serviço, para quais pessoas vai contar sobre seu estado, quais devem ser as mudanças imediatas e necessárias na sua vida, etc. No Meio da gravidez, durante o Sentindo-se grávida, ela precisa decidir, entre outras coisas, se deve seguir ou não as orientações médicas e os ensinamentos de conhecidos, e, também, como se deve comportar, de forma geral. Finalmente, ao Fim da gravidez, as decisões parecem estar relacionadas principalmente ao local onde o parto será realizado e quem o realizará, quem cuidará das crianças e da casa durante a hospitalização, quem ajudará no cuidado de si e da criança após o parto, etc.

Além das decisões principais em cada etapa, existem algumas que são comuns a todas elas, como é o caso, por exemplo, das decisões referentes á compra do enxoval e pertences do bebê.

Finalmente, o desenvolvimento do Vivenciando a Gravidez se dá como parte da vivência do Processo de vida da mulher, o qual é formado pelo conjunto das várias áreas de sua vida e suas inter-relações, o que envolve também seu ambiente social. Assim, a gravidez surge na vida da mulher a partir da priorização de uma destas áreas, a sexual, seja através da elaboração de planos e projetos específicos a esta área, ou simplesmente através do exercício da prática sexual.

Por isto, o Vivenciando a gravidez se dá inserido em um contexto que o influencia. E é este contexto que faz com que a experiência de Vivenciar a gravidez seja única para cada mulher e para cada gravidez, pois a cada nova gravidez se soma a experiência da anterior, além do fato de a mulher encontrar-se inserida já em outro 
contexto, o qual é dinâmico, visto que não envolve apenas o ambiente físico, e sim o conjunto de vários fatores entre os quais se destaca o ambiente familiar, cultural, social, econômico, histórico, político e outros, sendo possível destacar, por exemplo, a relação entre o estado civil e o nível de conhecimento das mulheres sobre métodos de anticoncepção e fisiologia da reprodução, o que, de certa forma, influencia diretamente o Vivendo um relacionamento sexual e, indiretamente, o Vivenciando a gravidez.

\section{IMPLICAÇÕES PARA A ENFERMAGEM}

A teoria substantiva Vivenciando a Gravidez surgiu a partir da experiência vivida pelas mulheres neste estado. Como é grande a probabilidade de a maioria das mulheres em idade adulta já terem ou virem a viver esta experiência, e como as inúmeras alterações que dela decorrem, mesmo que por um período limitado, são bastante passíveis de ocorrer, considero que a presente teoria possui significativas implicações, tanto para a prática como para o ensino e a pesquisa, inclusive suscitando o desenvolvimento de teorias em enfermagem.

Este estudo fornece subsídios para a prática por constituir um referencial teórico diferenciado, já que até o momento a enfermagem tem centrado a assistência prestada à mulher em estado de gravidez no modelo biomédico, ou seja, não no indivíduo e sim no aspecto curativo. Ele também fornece um marco teórico mais abrangente para o ensino da enfermagem obstétrica, pois, à medida que ordena na forma de processos, sub-processos e categorias os vários aspectos da experiência da mulher em estado de gravidez, conforme sua própria perspectiva, valorizando sua percepção, contexto e relações sociais, aprimora e amplia o elenco de conhecimentos que norteiam o ensino nesta área. Isto favorece, facilita e fundamenta o ensino de uma assistência mais global e individualizada à mulher.

Além disso, a forma como esta teoria substantiva foi desenvolvida, bem como os constructos desenvolvidos, também amplia, em muito, a perspectiva para o desenvolvimento de futuras pesquisas relacionadas ao tema em questão, as quais poderão reinterpretar não só os processos, conceitos e constructos desenvolvidos, mas também as suas relações e inter-relações, o que, por sua vez, permitirá uma consistência crescente no corpo de conhecimentos envolvidos. Finalmente, o desenvolvimento da teoria substantiva Vivenciando a Gravidez pode contribuir de forma particular na compreensão do que seja uma teoria substantiva, podendo, por sua vez, suscitar um maior interesse por parte dos profissionais enfermeiros em desenvolver constructos e teorias, seja em relação a este mesmo fenômeno ou a outros experienciados por seres humanos na qualidade de clientes e/ou pacientes. 


\section{LIVING THE PREGNANCY: PROCESSES AND SUB- PROCESSES OF A THEORY BASED ON DATA}

This paper shows the results of a qualitative study, that adopted as a methodological line the "Grounded Theory" and as a method to the data collection the participating observation. The goal was to explore and understand the period of a pregnancy, as seen by pregnant women. The data were collected with four sample groups, including 96 women, from January to December 1987. Results of the study are a starting point to a substantive theory in development, "Living the Pregnancy": a dynamic process occurring in the woman's life within a context. Living such a process could be planned or not. Such course of living occurs along four sequential and interconnected stages, which were called Preceding the Beginning, the Beginning, the Middle, and the End of pregnancy.

UNITERMS: woman, pregnancy, living the pregnancy, and living experience

\section{VIVIENDO EL EMBARAZO: PROCESOS Y SUB-PROCESOS DE UNA TEORÍA FUNDAMENTADA EN LOS DATOS}

Este artículo presenta los resultados de un estudio cualitativo, que adoptó como línea metodológica la "Grounded Theory" y como método de colecta de datos la observación participante. El objetivo fue explorar y comprender el período de un embarazo a partir de la perspectiva de mujeres embarazadas. Los datos fueron colectados junto a cuatro grupos de muestras, totalizando 96 mujeres, en el período de enero a diciembre de 1987, los resultados del estudio dieron origen a una teoría substantiva, en desarrollo, "Viviendo el embarazo": proceso dinámico que ocurre en la vida de la mujer, dentro de un contexto espacio-temporal. La vivencia de este proceso puede, o no, ser planeada y se da en cuatro etapas secuénciales e interrelacionadas: Precediendo el inicio, el Inicio, el Medio y el Fin del embarazo.

UNITERMOS: mujer, embarazo, viviendo el embarazo, experiencia vivida

\section{REFERÊNCIAS BIBLIOGRÁFICAS}

01. CHENITZ, W. Z., SWANSON, J. M. From practice to grounded theoryqualitative research in nursing. Menlo Park: Addison-Wesley, 1986. p. 259. 
02. FIELD, P. A., MORSE, J. M. Nursing research: the application of qualitative approaches. Maryland: Aspen Publication, 1985. p. 167.

03. GLASER, G. B., STRAUSS, A. L. The discovery of grounded theory: strategies for qualitative research. Chicago: Aldine Publishing, 1976. p. 271.

04. LEININGER, M. M. Qualitative research methods in nursing. Orlando: Grune \& Stration, 1985. p. 361.

05. LOFLAND, J. Analyzing social settings: a guide to qualitative observation and analysis. Belmont: Wadsworth Publishing, 1971.

06. MARCON, S. S. Vivenciando a gravidez. Florianópolis, p. 383. Dissertação (Mestrado) - Departamento de Enfermagem, Universidade Federal de Santa Catarina, 1989.

07. PEARSALL, M. Participant observation as role a method in behavioral research. Nurs.Res., New York, v. 14, n. 1, p. 37-42, 1965.

08. WILSON, H. S. Limiting intrusion-social control of outsiders in a healing community: an illustration of qualitative o comparative analysis. Nurs.Res., New York, v. 26, n. 2, p. 103-11, 1977. 